\title{
Jangkauan Wilayah Pelayanan Pasar Tradisional Somoroto di Kecamatan Kauman Kabupaten Ponorogo
}

\author{
Abbima Indra Nurcahya ${ }^{1}$ \\ Staf Kementerian Pekerjaan Umum, Jakarta \\ Artikel Masuk : 20 Juni 2014 \\ Artikel Diterima : 31 Juli 2014
}

\begin{abstract}
Abstrak: Pasar tradisional merupakan tempat perdagangan asli yang masih mempunyai ciriciri perdagangan tradisional sesuai dengan budaya lokal. Dengan semakin banyaknya perubahan pada pemenuhan kebutuhan masyarakat, maka barang dagangan yang diperjualbelikan di pasar tradisional tidak hanya barang asli setempat saja. Banyak barang dagangan yang berasal dari daerah lain dan bahkan berasal dari produk industri skala besar. Penelitian ini bertujuan untuk mengetahui jangkauan wilayah pelayanan Pasar Tradisional Somoroto Kecamatan Kauman, Kabupaten Ponorogo dengan menggunakan mix method: deskriptif kuantitatif dan kualitatif dengan empat analisis. Pertama, analisis mekanisme atau proses jual beli barang. Kedua, analisis pemilihan lokasi pedagang dan pembeli dalam berbelanja di Pasar Tradisional Somoroto. Ketiga, analisis asal pedagang dan pembeli. Keempat, analisis jaringan pelayanan pasar tradisional Somoroto. Hasil dari penelitian ini adalah sebagai berikut: pertama, sebagai tempat koleksi distribusi komoditas, pasar tradisional Somoroto mempunyai jenis komoditas dan lingkup layanan yang berbeda-beda. Kedua, barang dagangan kebanyakan masih di import dari luar wilayah Kecamatan Kauman dan Kabupaten Ponorogo. Ketiga, mekanisme jual beli yang mencirikan budaya lokal seperti "nempur", "ngutang" dan "nempil" masih berlaku. Keempat, alasan pemilihan lokasi di pasar tradisional bukan semata-mata harga yang murah, melainkan karena adanya ikatan untuk melakukan interaksi sosial.
\end{abstract}

Kata kunci: Pasar Tradisional, Wilayah Pelayanan

\begin{abstract}
Traditional markets are trading places which still have the original characteristics of traditional trade in accordance with the local culture. Because a number of changes to meet the needs of society, the merchandises that are bought and sold in traditional markets is not only local genuine goods. The merchandises mostly coming from other regions and even comes from large-scale industrial products. This syudy aims to determine the service coverage of Somoroto traditional market in Kauman Subdistrict, Ponorogo District using mixed methods: quantitative and qualitative descriptive analysis. First, analysis of the mechanism or process of buying and selling goods. Second, analysis of location choosing traders and buyers in the shop at traditional markets Somoroto. Third, the analysis of the origin of traders and buyers. Fourth, the service area network analysis Somoroto traditional markets. The results of this study are as follows: first, as a collection of commodity distribution, Somoroto traditional markets have commodities and scope of different services.
\end{abstract}

\footnotetext{
${ }^{1}$ Korespondensi Penulis: Kementerian Pekerjaan Umum, Jakarta, Indonesia Email: abbimaindra@yahoo.com
} 
Second, most of the merchandises is imported from outside of the Kauman sub-district and Ponorogo district. Third, selling mechanism that characterizes the local culture as "nempur", "ngutang" and "nempil" are still applied. Fourth, the reason for choosing location in Somoroto traditional markets is not merely a cheap price, but also the ties to social interaction.

Keywords: Traditional Market, Service Coverage

\section{Pendahuluan}

\section{Latar Belakang}

Sebagai tempat aktifitas perdagangan masyarakat, perkembangan pasar tradisional tidak terlepas dari pertumbuhan suatu wilayah. Bagi masyarakat Jawa pasar tradisional bukan hanya sebagai tempat jual beli semata, melainkan juga sebagai tempat berinteraksi sosial (Aliyah.et al, 2007).Pasar tradisional Somoroto sebagai pusat aktifitas perdagangan di Kecamatan Kauman dan sekitarnya telah ikut serta dalam memajukan wilayah di Kecamatan Kauman. Pedagang yang berjualan di pasar tradisional Somoroto merupakan penduduk di sekitar pasar, sehingga hal tersebut memberikan dampak positif bagi penyerapan tenaga kerja di Kecamatan Kauman.

Permasalahan yang muncul adalah mengenai komoditas yang diperjualbelikan di pasar tradisional Somoroto merupakan komoditas yang bukan asli setempat. Komoditas seperti buah, sayur, ikan, daging dan lain sebagainya diimport dari luar wilayah Kecamatan Kauman. Selama ini pasar tradisional Somoroto hanya sebagai tempat distribusi barang import, bukan sebagai tempat koleksi komoditas asli setempat.

Meskipun pasar tradisional berperan penting dalam penyerapan tenaga kerja di Kecamatan Kauman, tetapi juga sangat bergantung dengan komoditas dari luar wilayah. Komoditas yang asli sekitar pasar merupakan sektor pertanian, tetapi pemasarannya juga tidak melalui pasar tradisional Somoroto. Dengan demikian keberadaan pasar tradisional Somoroto seperti dua sisi yang berbeda, di satu sisi menyerap tenaga kerja (pedagang) dan di sisi lain tidak mampu menjadi pengembang komoditas di Kecamatan Kauman.

\section{Tujuan dan Sasaran}

Penelitian ini bertujuan untuk mengetahui jangkauan wilayah pelayanan pasar tradisional Somoroto di Kecamatan Kauman, Kabupaten Ponorogo. Adapun sasaran dalam penelitian ini adalah:

1. Menganalisis mekanisme atau proses jual beli di pasar tradisional Somoroto.

2. Menganalisis pemilihan lokasi pedagang dan pembeli di pasar tradisional Somoroto.

3. Menganalisis asal wilayah pedagang dan pembeli di pasar tradisional Somoroto.

4. Menganalisis jaringan pelayanan pasar tradisional Somoroto.

\section{Metodologi Penelitian}

Penelitian ini menggunakan metode campuran, yaitu metode penelitian deskriptif kuantitatif dan kualitatif dengan empat analisis. Pertama, analisis mekanisme atau proses jual beli barang. Kedua, analisis pemilihan lokasi pedagang dan pembeli dalam berbelanja di Pasar Tradisional Somoroto. Ketiga, analisis asal pedagang dan pembeli. Keempat, analisis jaringan pelayanan pasar tradisional Somoroto. 
Dalam penelitian ini disebar kuesioner kepada pedagang dan pembeli dan juga dilakukan wawancara mendalam. Untuk kuesioner, hasilnya diolah dengan pendekatan deskriptif kuantitatif, sementara itu untuk wawancara dilakukan langkah pengkodean data.

\section{Gambaran Umum Wilayah Studi}

Pertumbuhan penduduk yang semakin pesat terutama di negara-negara berkembang telan menyebabkan banyak perubahan dalam kehidupan. Penduduk yang bertambah besar di Kecamatan Kauman menyebabkan pemenuhan kebutuhan penduduk semakin meningkat. Pasar tradisional Somoroto yang terletak di Kecamatan Kauman memegang peranan penting dalam penyaluran kebutuhan hidup penduduk.

Pasar tradisional Somoroto menjadi simpul dalam perkembangan wilayah di Kecamatan Kauman, maupun kecamatan sekitarnya, semisal Kecamatan Sukorejo yang jaraknya cukup dekat dengan pasar somoroto. Pasar Somoroto berkembang besar sampai saat ini merupakan bukti bahwasanya pertumbuhan di Kecamatan Kauman tidak bisa terlepaskan dari keberadaan pasar tradisional tersebut.

Sektor pertanian di Kabupaten Ponorogo terdiri dari komoditi tanaman padi, jagung, ubi kayu dan ubi jalar. Untuk tanaman padi yang paling potensial adalah di Kecamatan Sukorejo, Balong, Babadan, Pulung, Jenangan dan Kauman. Komoditi tanaman jagung potensial di Kecamatan Sawoo, Pulung, Jambon, Bungkal dan Sambit. Sedangkan komoditi ubi kayu ada di Kecamatan Ngrayun, Sawoo, Sambit, Pulung dan Jambon. Komoditi ubi jalar potensial di Kecamatan kecamatan Ngrayun, Sooko, Pulung, Sambit dan Pudak.

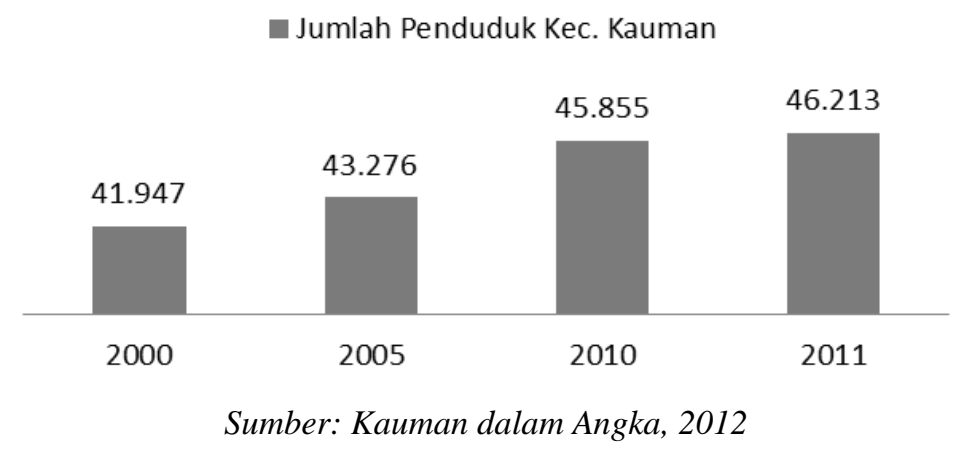

Gambar 1. Jumlah Penduduk Kecamatan Kauman Tahun 2000, 2005, 2010, dan 2011

\section{Kajian Teori}

\section{PasarTradisional}

Menurut Brian Berry (1989) pasar adalah suatu tempat di mana terjadi proses tukar menukar. Proses ini dapat berlangsung jika sejumlah penjual dan pembeli berkomunikasi satu sama lain dan berakhir dengan keputusan untuk memindahtangankan barang-barang yang diperjualbelikan tersebut kepada pembeli. Sementara itu Geertz (1989), berpendapat bahwasanya pasar adalah lingkungan yang dari sudut pandangannya merupakan gejala alami dan juga gejala kebudayaan dan keseluruhan dari kehidupannya dibentuk oleh pasar itu.

Pasar tradisional tidak sepenuhnya dimiliki oleh perusahaan atau pedagang besar. Tetapi terdiri dari pedagang individu dan pedagang kelompok kecil (Kim.et al, 2004). Yang mencirikan pasar tradisional berbeda dari pasar modern adalah dimana pasar tradisional bersifat sliding price (Geertz). 
Menurut Geertz ada tiga sudut pandang yang ada di pasar yaitu: (1) pasar sebagai arus barang dan jasa menurut pola tertentu; (2) pasar sebagai rangkaian mekanisme ekonomi untuk memelihara dan mengatur arus barang dan jasa serta (3) pasar sebagai sistem dan kebudayaan dimana mekanisme itu tertanam.

Cara-cara perdagangan tradisional yang sudah ada di pasar-pasar Jawa sejak jaman Mataram Kuno adalah sebagai berikut (Nastiti, 2003):

1. Transaksi. Pada masa Jawa kuno telah dikenal 2 (dua) bentuk transaksi, yaitu: (a) transaksi yang dilakukan secara barter dengan berdasarkan atas perbandingan satuan yang telah ditetapkan oleh kedua pihak; (b) transaksi dilakukan dengan mempergunakan mata uang sebagai alat penukar.

2. Adanya tatap muka secara langsung.

3. Adanya tawar menawar.

\section{Jangkauan Wilayah Pelayanan}

Christaller (1933), mengemukakan teori pertumbuhan perkotaan yang pada dasarnya menyatakan bahwa pertumbuhan kota tergantung spesialisasinya dalam fungsi pelayanan perkotaan. Wilayah perdagangan adalah gambaran wilayah geografis yang sederhana dengan memperlihatkan pergerakan konsumen menuju lokasi aktivitas pusat perdagangan, atau dengan kata lain suatu wilayah di mana konsumen dapat ditarik untuk berkunjung ke suatu pusat perdagangan (Lewison, 1989).

\section{Analisis}

\section{Analisis Mekanisme Jual Beli}

Mekanisme atau proses jual beli yang dilakukan antara pedagang dan pembeli di pasar tradisional Jawa terdiri dari dua jenis, yaitu (1) transaksi yang terdiri dari barter dan tunai; (2) adanya tawar menawar.
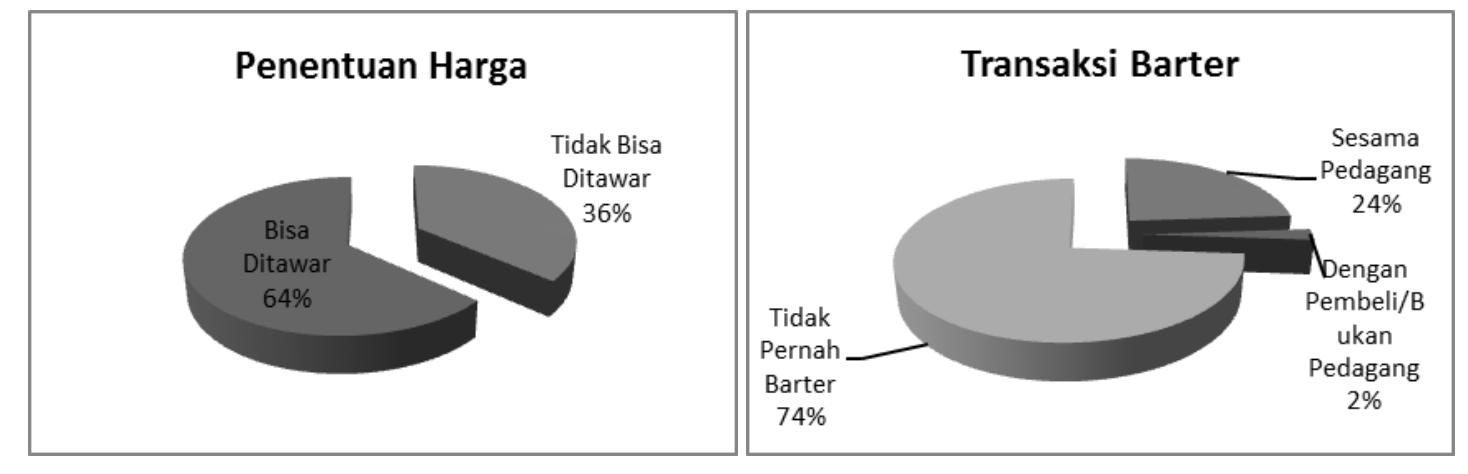

\section{Gambar 2. Penentuan Harga dan Transaksi Barter di Pasar Tradisional Jawa}

Transaksi secara barter di Pasar Tradisional Somoroto yang pernah dilakukan adalah sesama pedagang dengan persentase pedagang yang pernah melakukan adalah sebesar 24 $\%$. Barter diantara pedagang ini biasanya digunakan untuk keperluan hidup sehari-hari. Sebagai contoh, pedagang sayur melakukan barter dengan pedagang bawang. Pedagang sayur akan menggunakan bawang untuk keperluan memasak di rumah, sementara itu pedagang bawang akan menggunakan sayur juga untuk memasak. Begitupun yang terjadi pada pedagang lain nya yang pernah melakukan barter. 
Selanjutnya ada yang disebut dengan istilah "nempur", dimana hal ini sudah jarang ditemui tetapi ada beberapa yang masih menggunakan aktifitas tersebut. Istilah "nempur" berkaitan dengan aktifitas berhutang beras atau ketan kepada pedagang. Aktifitas lainnya yang masih ada di Pasar Tradisional Somoroto adalah "nempil". "Nempil" sebenarnya berkaitan dengan barang dagangan yang tidak banyak jumlahnya. Maksudnya pembeli menginginkan suatu barang dagangan tetapi dengan menggunakan uang seadanya, kemudian pedagang juga akan memberikan barang tanpa ukuran yang pasti. Pokoknya hal tersebut sesuai kesepakatan antara pedagang dan pembeli.Sebagai contoh, ketika cabai harga nya sangat mahal tentu saja orang akan berpikir ulang untuk membeli kiloan. Oleh karenanya pembeli memilih "nempil"cabai, semisal dengan uang seribu rupiah, lalu pedagang akan memberikan beberapa biji cabai. Selanjutnya apabila ibu rumah tangga ingin memasak sayur sop, tetapi tidak ingin membeli banyak sayur, maka ibu tersebut akan "nempil" sayur dengan sejumlah uang, lalu pedagang akan memberikan bahan sayur sop lengkap meskipun tiap jenis sayur jumlah nya tidak banyak.

\section{Analisis Pemilihan Lokasi Pedagang dan Pembeli}

Pedagang yang berjualan di Pasar Tradisional Somoroto dalam berdagang rupanya mempunyai berbagai alasan. Masalah biaya sewa lapak atau kios atau tempat berdagang yang mengatakan setuju ada sekitar $89 \%$ responden dan sekitar $11 \%$ mengatakan tidak setuju. Besarnya sewa di Pasar Tradisional Somoroto terdiri dari 3 kelas. Ada pedagang yang ditarik sebesar Rp. 1.000,-, Rp. 3.000,- dan Rp. 5.000,-. Besarnya biasa sewa yang berbeda tersebut menentukan lokasi, besar dan bentuk tempat berdagang yang digunakan. Untuk pedagang-pedagang yang kecil biasanya di tarik Rp. 1.000,- dan untuk pedagang menengah dan besar sebesar Rp. 3.000,- dan Rp. 5.000,-. Dari sekitar 89 \% responden pedagang mengatakan bahwasanya alasan sewa yang murah menjadi daya tarik kenapa mau berdagang di Pasar Tradisional Somoroto.

Tabel 1. Alasan Pemilihan Lokasi Pedagang di Pasar Tradisional Somoroto

\begin{tabular}{c|c|c|c|c|c}
\hline No. & Alasan & Biaya Sewa & Jumlah Pembeli & Dekat Rumah & $\begin{array}{c}\text { Tersedianya } \\
\text { Transportasi Umum }\end{array}$ \\
\hline 1. & Setuju & $89 \%$ & $86 \%$ & $83 \%$ & $74 \%$ \\
\hline 2. & Tidak Setuju & $11 \%$ & $14 \%$ & $17 \%$ & $26 \%$ \\
\hline
\end{tabular}

Alasan adanya pembeli yang banyak, dari responden pedagang yang mengatakan setuju ada sekitar $86 \%$ dan sekitar $14 \%$ mengatakan tidak setuju. Dengan adanya jumlah pembeli yang banyak tentu saja akan memberikan kesempatan bagi pedagang untuk menjual barang dagangannya. Dengan demikian pedagang akan terus bertahan berjualan di Pasar Tradisional Somoroto.

Lokasi yang dekat dengan rumah juga menjadi pertimbangan bagi pedagang di Pasar Tradisional Somoroto. Ada sekitar 83 \% yang mengatakan setuju jika lokasi pasar yang dekat menjadikan alasan berjualan. Sementara itu ada sekitar $17 \%$ yang tidak setuju jika lokasi yang dekat menjadikan alasan kenapa berjualan di Pasar Tradisional Somoroto.

Sekitar $74 \%$ responden setuju jika ketersediaan sarana transportasi menjadi alasan mau berdagang di Pasar Tradisional Somoroto, sementara sekitar $26 \%$ mengatakan tidak setuju. Padahal rata-rata pedagang sudah mulai berjualan sekitar jam 3 dini hari. Artinya sarana transportasi umum ini seharusnya tidak menjadi alasan, mengingat sudah banyak kendaraan bermotor pribadi. 
Tabel 1. Alasan Pemilihan Lokasi Pembeli di Pasar Tradisional Somoroto

\begin{tabular}{l|l|l|l|l|l}
\hline No. & Alasan & Harga & Pedagang Banyak & Keragaman Barang & Dekat Rumah \\
\hline 1. & Setuju & $100 \%$ & $92 \%$ & $75 \%$ & $83 \%$ \\
\hline 2. & Tidak Setuju & $0 \%$ & $8 \%$ & $25 \%$ & $17 \%$ \\
\hline
\end{tabular}

Pemilihan lokasi bagi tiap-tiap pembeli di pasar somoroto rupanya berbeda-beda. Berdasarkan sampel hasil penelitian yang meliputi alasan harga, jumlah pedagang, keragaman barang dan lokasi dekat terlihat bahwasanya terdapat beberapa kesamaan dan perbedaan. Masalah harga rupanya menjadi pendorong utama bagi pembeli untuk berbelanja di Pasar Tradisional Somoroto. Jumlah pembeli yang mengatakan setuju masalah harga yang murah menjadi alasan berbelanja adalah sebesar $100 \%$. Artinya seluruh pembeli yang berbelanja di Pasar Tradisional Somoroto semuanya beralasan jika harga barang di pasar adalah murah.

Selanjutnya mengenai jumlah pedagang di Pasar Tradisional Somoroto yang jumlah nya banyak. Dari keseluruhan responden mengungkapkan yang setuju jika jumlah pedagang banyak adalah sekitar $92 \%$, sementara yang menjawab tidak setuju adalah sekitar $8 \%$. Dengan banyaknya jumlah pedagang tentunya akan menguntungkan bagi calon pembeli. Calon pembeli bisa memilih pedagang yang sekiranya tidak antri atau yang bisa memberikan harga yang lebih murah.

Keragaman barang adalah alasan selanjutnya bagi pembeli dalam berbelanja di Pasar Tradisional Somoroto. Responden pembeli yang mengatakan setuju jika keragaman barang adalah salah satu alasan dalam berbelanja adalah sekitar $75 \%$. Responden yang tidak setuju keragam barang adalah sekitar $25 \%$. Keragaman barang seperti sayur atau bumbubumbuan terlihat jelas di pasar somoroto.

Lokasi atau jarak pasar juga menjadikan alasan mengapa pembeli mau datang untuk berbelanja di Pasar Tradisional Somoroto. Terdapat 83 \% responden yang setuju jika lokasi pasar yang dekat dengan rumah adalah alasan mereka berbelanja. Selanjutnya ada sekitar $17 \%$ yang tidak setuju jika lokasi yang dekat adalah alasan dalam berbelanja di Pasar Tradisional Somoroto.

\section{Analisis Asal Pedagang dan Pembeli}

Pedagang yang berjualan di pasar tradisional Somoroto kebanyakan berasal dari wilayah Kecamatan Kauman dimana yang berasal dari Kecamatan Kauman sebesar 87,5 \% dan yang berasal dari luar Kecamatan Kauman 12,5 \%. Dengan demikian keberadaan pasar tradisional Somoroto telan menjadi salah satu penyerapan tenaga kerja di sekitar pasar.

Penduduk yang berada di sekitar pasar merupakan penduduk yang mendapatkan dampak yang paling besar dari adanya pasar tradisional Somoroto. Pedagang yang berjualan di pasar tradisional Somoroto sebagian besar merupakan pedagang yang berasal dari sekitar pasar. Banyaknya pedagang dari sekitar pasar Somoroto mengindikasikan bahwasanya pasar tradisional Somoroto juga berperan dalam penyerapan tenaga kerja.

Pembeli di Pasar Tradisional Somoroto merupakan pembeli yang menjadi wilayah layanan pasar somoroto. Pembeli tersebut tidak hanya berasal dari dalam wilayah Kecamatan Kauman, melainkan juga dari luar wilayah Kecamatan Kauman.Desadesaseperti Plosojenar, Somoroto, Maron dan Carat menyumbang jumlah pembeli yang cukup besar dikarenakan lokasi geografis yang menguntungkan. Letak desa-desa tersebut cukup dekat dengan Pasar Tradisional Somoroto dibandingkan dengan desa-desa lainnya. 
Desa Sukosari, Nglarangan, Bringin dan Pengkol bahkan penduduknya hampir tidak ada yang berbelanja di Pasar Tradisional Somoroto.

Letak pasar somoroto memang tidak di tengah-tengah Kecamatan Kauman, melainkan berada di Desa Plosojenar dan Desa Somoroto yang letaknya di pinggir kecamatan. Wilayah yang menjadi letak pasar somoroto justru dekat dengan Kecamatan Sukorejo atau Jambon daripada dengan desa-desa di Kecamatan Kauman. Desa Sukosari, Nglarangan, Bringin, Pengkol justru lebih dekat dengan wilayah Kecamatan Balong.
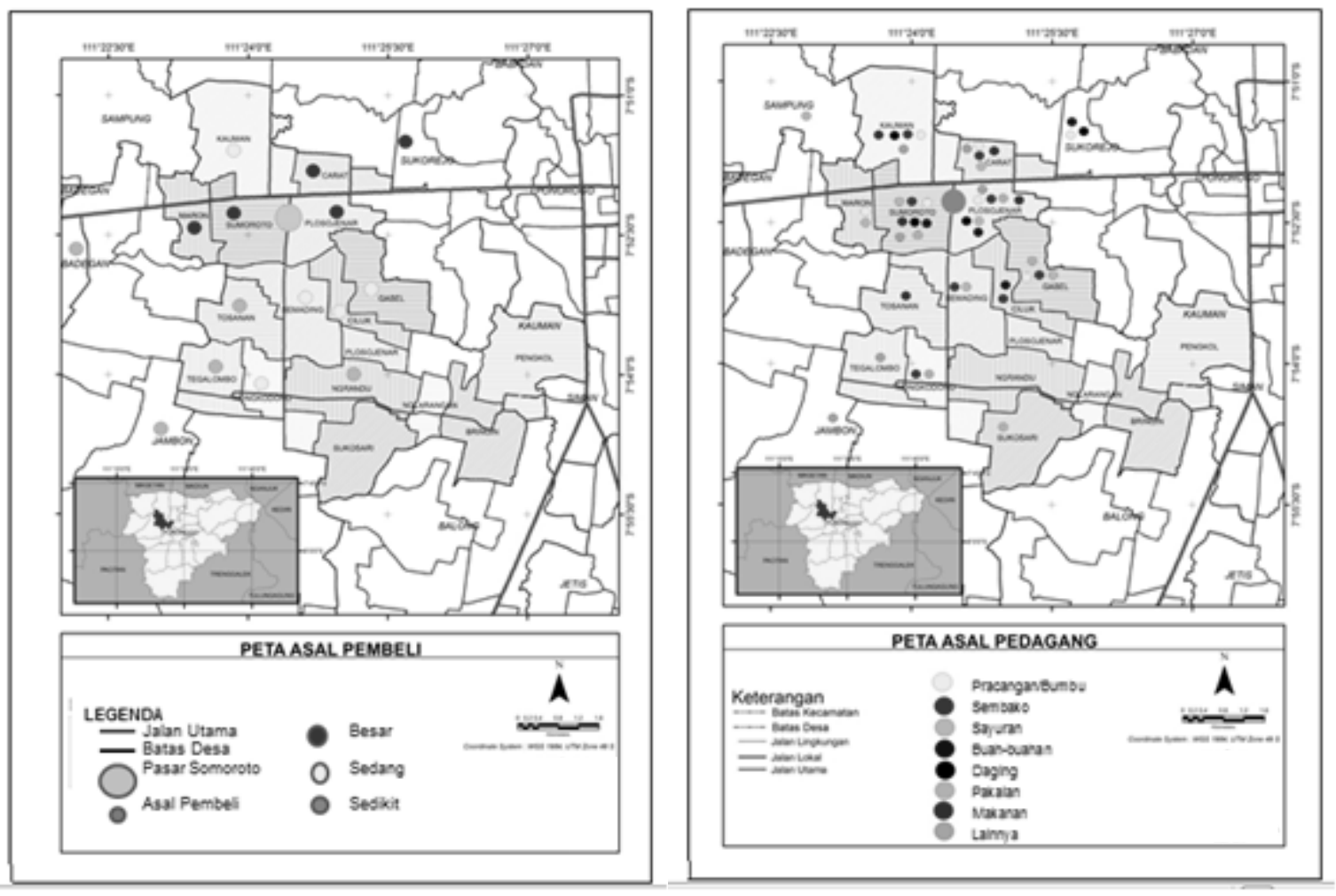

Gambar 3. Peta Asal Pembeli dan Pedagang di Pasar Sumuroto

\section{Analisis Jaringan Pelayanan Pasar Tradisional Somoroto}

Sebagai suatu pusat pelayanan, pasar tradisional Somoroto mempunyai peran dalam hal kolektifitas dan pendistribusian barang dagangan yang diperjual belikan. Pelayanan barang dagangan tidak hanya kepada konsumen langsung atau pembeli untuk kebutuhan sehari-hari saja, melainkan ada pasar lain atau toko-toko. Pasar dan toko lainnya kemudian akan menjual lagi barang dagangan kepada konsumen yang berada dalam lingkup wilayah pelayanannya. Sehingga wilayah pelayanan barang dagangan akan membentuk hierarki yang bertingkat.

Sebagai pusat pelayanan yang terletak di Kecamatan Kauman, pasar tradisional Somoroto tidak hanya melayani masyarakat di sekitar pasar. Pasar Somoroto juga memberikan layanan kepada pasar-pasar kecil disekitarnya, seperti pasar Badegan, pasar Jambon, pasar Ngumpul dan bahkan pasar kecil dengan skala desa yaitu pasar Tegalombo. 

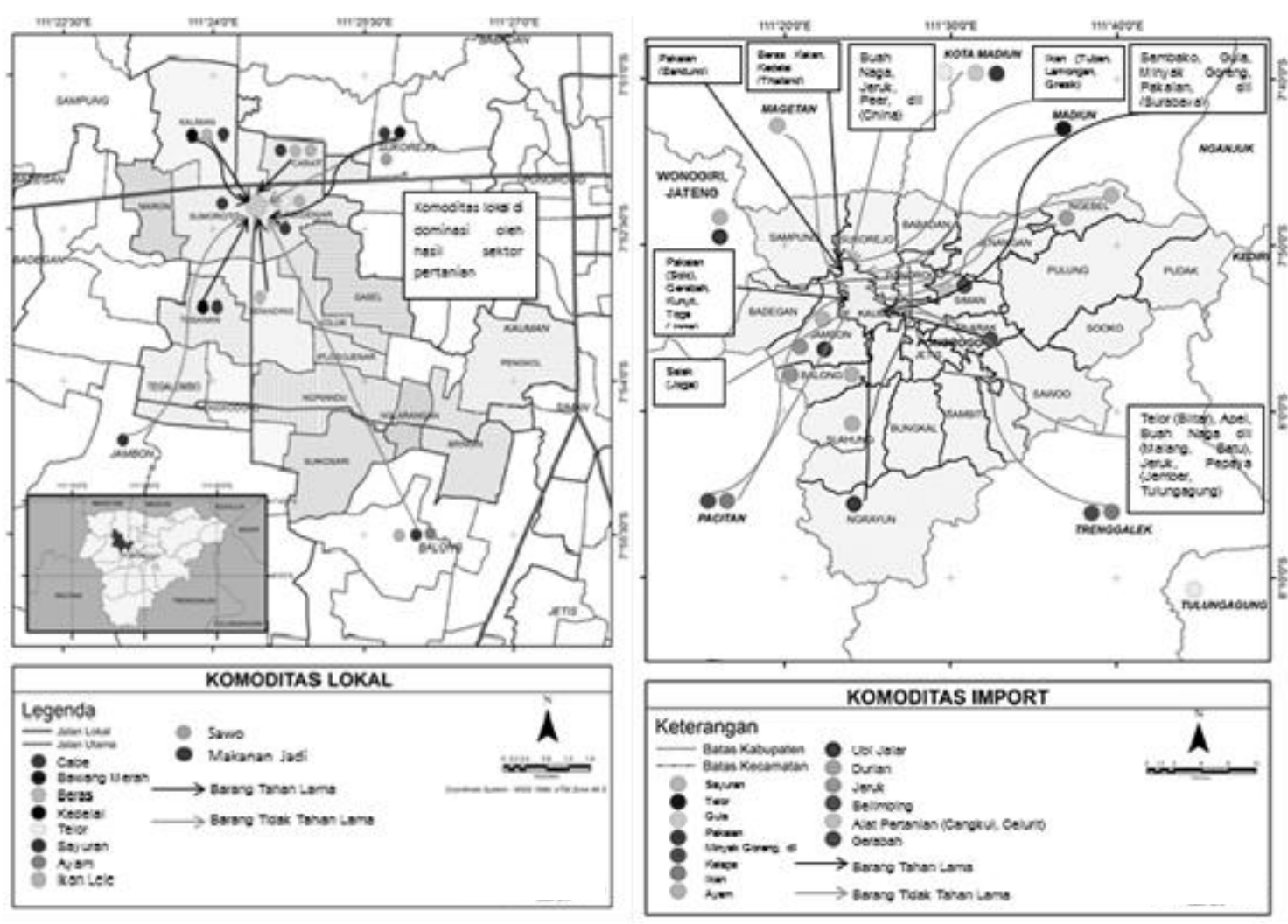

Gambar 4. Peta Persebaran Komoditas Lokal dan Komoditas Import

Jenis komoditas yang diimport atau berasal dari luar wilayah sekitar pasar tradisional Somoroto sangatlah beragam. Komoditas tersebut tidak hanya berasal dari Ponorogo, melainkan banyak yang berasal dari luar Ponorogo dan bahkan luar Indonesia. Komoditas yang tahan lama kebanyakan berasal dari luar wilayah, sementara itu untuk komoditas yang tidak tahan lama banyak yang berasal dari dalam wilayah.

Jenis komoditas yang tahan lama dan diimport dari luar wilayah misalnya seperti sembako (minyak goreng, kecap, dll), dimana barang tersebut berasal dari Surabaya atau Kota Madiun. Gula berasal dari Madiun, pakaian ada yang berasal dari Solo, Bandung, Tulungagung dan juga Kota Madiun. Gerabah berasal dari Kecamatan Mlarak, Ponorogo dan juga ada yang berasal dari Jogja.

Komoditas yang berasal dari import tidak hanya komoditas yang tahan lama saja, melainkan ada beberapa komoditas seperti buah-buahan diimport dari China, Kota Malang dan Kota Batu serta Jember. Dari arus distribusi komoditas yang masuk di pasar tradisional Somoroto terlihat bahwasanya ada beberapa komoditas yang tidak tahan lama juga berasal dari wilayah yang cukup jauh.

Sementara itu barang yang asli lokal wilayah sekitar pasar tradisional Somoroto kebanyakan merupakan komoditas pertanian dan kebutuhan primer (makanan). Beras dan kedelai merupakan komoditas lokal yang diperjualbelikan di pasar tradisional Somoroto. Komoditas-komoditas tersebut merupakan barang yang sifatnya tahan lama. Komoditas lokal yang tidak tahan lama yaitu ada cabe, sayuran, buah dan juga ikan air tawar semisal ikan lele.

Barang dagangan yang secara tradisional merupakan komoditas asli masyarakat sekitar Ponorogo yaitu komoditas primer. Komoditas primer merupakan jenis komoditas yang sejak awal adanya pasar Somoroto menjadi komoditas yang diperjual belikan. 
Sementara itu untuk komoditas sekunder dan tersier kebanyakan diimport dari luar wilayah.

Barang dagangan pracangan mempunyai jangkauan wilayan layanan terhadap pasar Tegalombo, yang lingkupnya merupakan pasar kecil atau skala desa. Kemudian untuk barang dagangan sembako, mempunyai lingkup wilayah layanan yang lebih luas, meliputi pasar Samsung, pasar Badegan, pasar Jambon. Pasar-pasar tersebut nantinya akan melayani penduduk yang dekat.

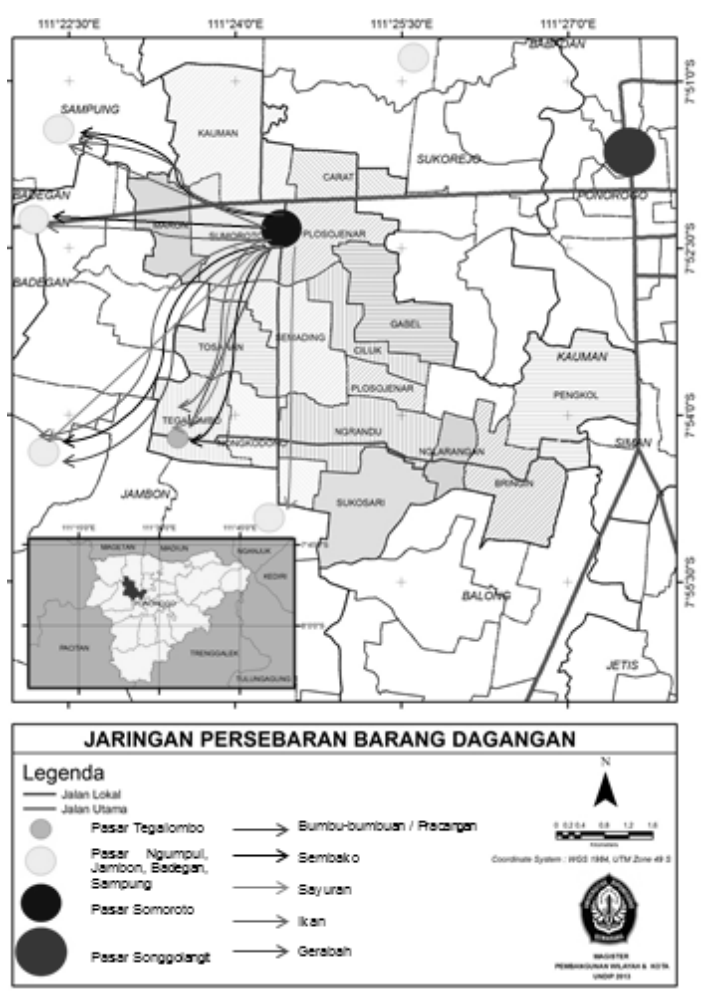

\section{Gambar 5. Peta Jaringan Persebaran Barang Dagangan}

Barang dagangan buah di pasar tradisional Somoroto berdasarkan hasil penelitian hanya dijual langsung kepada konsumen atau pembeli biasa. Berbeda dengan buah, untuk barang dagangan sayuran mempunyai lingkup wilayah pelayanan terhadap pasar Jambon, pasar Ngumpul dan pasar Tegalombo.

Barang dagangan daging ayam dan daging sapi di pasar tradisional Somoroto mempunyai lingkup wilayah layanan kepada konsumen langsung. Selanjutnya untuk barang dagangan ikan mempunyai lingkup wilayah layanan terhadap pasar Sampung, pasar Badegan, pasar Jambon dan pasar Tegalombo.

Barang dagangan gerabah mempunyai lingkup wilayah layanan terhadap pasar Jambon dan pasar Tegalombo. Sementara untuk barang dagangan pakaian tidak mempunyai wilayah pelayanan terhadap pasar lainnya. Pedagang lebih memilih mendapatkan barang dagangan pakaian langsung ke distributor besar, karena harga yang cenderung lebih murah di distributor.

Secara wilayah layanan, jenis barang dagangan yang mempunyai sifat tahan lama maupun tidak tahan lama mempunyai jangkauan wilayah pelayanan yang hampir sama. 
Sembako, sayuran maupun ikan laut, mempunyai wilayah layanan terhadap pasar-pasar lainnya.

Pasar tradisional Somoroto sebagai pusat pelayanan mempunyai jangkauan wilayah pelayanan yang lebih luas dibanding pasar-pasar lainnya yang ada di Ponorogo bagian barat. Penduduk yang ada di luar jangkauan wilayah layanan pasar Somoroto akan melakukan aktifitas perdagangan di pasar yang terdekat.

Pasar Tegalombo merupakan pasar tradisional tingkat desa yang letaknya termasuk wilayah administratif Kecamatan Kauman dan menjadi pasar yang mempunyai jarak terdekat dengan pasar tradisional Somoroto. Sehingga arus barang dan jasa ke pasar Tegalombo menjadi lebih banyak dibanding ke pasar-pasar lainnya.

Pasar-pasar tersebut menjadi simpul atau pembangkit dalam perkembangan dan pertumbuhan wilayah. Pasar tradisional Somoroto menjadi pusat pertumbuhan terbesar dikarenakan letaknya yang sangat strategis. Letak pasar Somoroto tepat berada di perempatan jalan, dimana jalan utama menghubungkan Kabupaten Ponorogo dan Kabupaten Wonogiri. Selanjutnya akses yang mudah dengan banyaknya angkutan umum berupa mini bus dan juga angkutan perdesaan (angkodes).

Dengan demikian, pasar tradisional Somoroto menjadi pusat pelayanan wilayah tertinggi di Ponorogo bagian barat. Selain melayani masyarakat di Kecamatan Kauman, pasar tradisional Somoroto juga melayani masyarakat di kecamatan lain, baik secara langsung maupun tidak langsung.

Layanan secara langsung ketika konsumen langsung melakukan aktifitas perdagangan di pasar tradisional Somoroto untuk keperluan kebutuhan sehari-hari. Kemudian ada pola layanan tidak langsung, dimana pasar tradisional Somoroto memberikan layanan distribusi komoditas kepada pasar-pasar atau pemilik kios. Pembeli atau konsumen yang berada di luar jangkauan wilayah pelayanan pasar tradisional Somoroto dan membeli di pasar-pasar atau kios tersebut, maka secara tidak langsung masuk sebagai lingkup wilayah layanan pasar Somoroto.

\section{Kesimpulan}

Dari hasil penelitian dan pembahasan terkait Jangkauan Wilayah Pelayanan Pasar Tradisional Somoroto di Kecamatan Kauman, Kabupaten Ponorogo, maka kesimpulan yang dihasilkan adalah pasar tradisional merupakan mekanisme dalam hal memelihara dan mengatur arus barang dan jasa. Barang dan jasa yang dipelihara merupakan komoditas yang secara turun temurun telah ada sejak awal berdirinya pasar tradisional. Aktifitas perdagangan yang masih menganut prinsip-prinsip tradisional masih dilakukan, meskipun komoditas yang diperjualbelikan sudah mulai bertambah banyak dan beragam. Komoditas yang ada di pasar tradisional berasal dari dalam wilayah sekitar pasar dan juga wilayah luar pasar (import). Sebagai tempat bagi koleksi distribusi komoditas, pasar tradisional sangatlah unik. Pasar tradisional mempunyai pola yang berbeda dibanding pasar modern. Pola koleksi dan distribusi komoditas sifatnya adalah langsung, dimana semua pelaku aktifitas jual beli mempunyai kesempatan yang sama untuk memasukkan barang dagangan di pasar tradisional.

Perkembangan pasar tradisional yang sedemikian rupa tidak terlepas dari historis kawasan. Pada umumnya masyarakat perdesaan yang mempunyai lahan sawah dan bertani akan memasarkan hasil pertanian, kemudian ada masyarakat lain yang bukan petani dan membutuhkan bahan pangan. Akhirnya muncul permintaan dan penawaran untuk pemenuhan kebutuhan hidup. Pasar yang dahulunya hanya tempat kecil kemudian berubah menjadi lokasi aktifitas perdagangan yang lebih besar. Pasar yang menempati lokasi strategis seperti di perempatan jalan merupakan simpul bagi perkembangan suatu 
wilayah atau kawasan. Dengan adanya satu pasar akan memunculkan pasar-pasar lainnya untuk memudahkan dalam hal pengaturan arus barang dan jasa kepada konsumen.

Pasar tradisional tidak hanya sebagai tempat bagi jual beli komoditas untuk pemenuhan kebutuhan. Pasar tradisional merupakan kearifan lokal dari wilayah yang bersangkutan dan menjadi identitas budaya masyarakat suatu wilayah. Interaksi sosial dan ekonomi akan dilakukan secara berbarengan di pasar tradisional.

Sebagai pusat pelayanan wilayah, pasar tradisional sangat dipengaruhi oleh kepadatan penduduk yang ada di dalam wilayah layanan. Tiap pasar mempunyai besaran atau luasan wilayah pelayanan yang berbeda-beda. Pasar tradisional mempunyai hierarki yang berbeda-beda, ada yang sanggup melayani hingga lingkup kawasan, skala kecamatan atau pasar yang hanya melayani skala desa.

Dengan adanya pusat-pusat pelayanan berupa pasar, turut berperan dalam pengembangan dan pambangunan wilayah. Banyaknya pasar juga menjadi ciri bahwa suatu wilayah lebih maju atau lebih besar dibanding wilayah lainnya yang tidak mempunyai pasar. Begitupun pasar tradisional yang mempunyai lingkup wilayah layanan lebih luas mencirikan bahwa wilayah tersebut merupakan wilayah yang lebih maju dibanding wilayah lain yang mempunyai pasar dengan lingkup wilayah layanan yang lebih kecil. Dengan demikian pertumbuhan suatu wilayah bisa dilihat dari besar kecil atau banyak sedikitnya pasar yang ada di wilayah tersebut.

\section{Daftar Pustaka}

Aliyah, I., Daryanto, T.J., \& Rahayu, M.J. 2007. Peran Pasar Tradisional dalam Mendukung Pengembangan Pariwisata Kota Surakarta. Surakarta: Gema Teknik UNS.

Berry, Brian J.L. 1967. Geography of Market Centers and Retail Distribution. Englewood Cliffs, Prentice Hall.

Djojodipuro, Marsudi. 1992. Teori Lokasi. Jakarta: LPFE - UI.

Geertz, Clifford. 1989. Penjaja dan Raja. Jakarta: Yayasan Obor Indonesia.

Ihsan. 1988. Studi Wilayah Pelayanan Pusat Belanja Wilayah di DKI Jakarta. Program Pascasarjana Institut Teknologi Bandung.

Kabupaten Ponorogo Dalam Angka Tahun 2012. Badan Pusat Statistik Kabupaten Ponorogo 2012.

Kecamatan Kauman Dalam Angka Tahun 2012. Badan Pusat Statistik Kabupaten Ponorogo 2012.

Kim, Ju Il., Lee C.M., Ahn K.H. 2004. Dongdaemon, a Traditional Market Place Wearing a Modern Suit: The Importance of The Social Fabric in Physical Redevelopments. Journal of Habitat International.

Lewison. 1989. Retailing. London: Merril Publishing Company.

Nastiti, Titi Surti. 2003. Pasar di Jawa: Masa Mataram Kuna Abad VIII - XI Masehi. Jakarta: Pustaka Jaya.

Rustiadi, Ernan. Saefulhakim, S, dan Panuju, Dyah R. 2011. Perencanaan dan Pengembangan Wilayah. Jakarta: Crespent Press dan Yayasan Pustaka Obor. 
168 Jangkauan Wilayah Pelayanan Pasar Tradisional Somoroto di Kecamatan Kauman Kabupaten Ponorogo

JURNAL WILAYAH DAN LINGKUNGAN, 2 (2), 157-168 